Review Article

\title{
Modulatory Mechanism of Polyphenols and Nrf2 Signaling Pathway in LPS Challenged Pregnancy Disorders
}

\author{
Tarique Hussain, ${ }^{1,2}$ Bie Tan, ${ }^{1,3}$ Gang Liu, ${ }^{1,2}$ Ghulam Murtaza, ${ }^{4}$ Najma Rahu, ${ }^{5}$ \\ Muhammad Saleem, ${ }^{6}$ and Yulong Yin ${ }^{1,2}$ \\ ${ }^{1}$ National Engineering Laboratory for Pollution Control and Waste Utilization in Livestock and Poultry Production, \\ Key Laboratory of Agro-Ecological Processes in Subtropical Region, Institute of Subtropical Agriculture Chinese Academy of Sciences, \\ Changsha, Hunan 410125, China \\ ${ }^{2}$ University of the Chinese Academy of Sciences, Beijing 10008, China \\ ${ }^{3}$ Hunan Collaborative Innovation Center for Utilization of Botanical Functional Ingredients and Hunan Collaborative Innovation \\ Center of Animal Production Safety, Changsha, Hunan 410000, China \\ ${ }^{4}$ Shaheed Benazir Bhutto University of Veterinary \& Animal Sciences, Sakrand, Sindh 67210, Pakistan \\ ${ }^{5}$ Department of Veterinary Microbiology, Faculty of Animal Husbandry and Veterinary Sciences, Sindh Agriculture University, \\ Tandojam, Sindh 70050, Pakistan \\ ${ }^{6}$ Food Engineering and Bioprocess Technology, Asian Institute of Technology, Bangkok 12120, Thailand
}

Correspondence should be addressed to Bie Tan; bietan@isa.ac.cn

Received 7 April 2017; Accepted 16 July 2017; Published 23 August 2017

Academic Editor: Alessandro Venditti

Copyright ( 2017 Tarique Hussain et al. This is an open access article distributed under the Creative Commons Attribution License, which permits unrestricted use, distribution, and reproduction in any medium, provided the original work is properly cited.

Early embryonic loss and adverse birth outcomes are the major reproductive disorders that affect both human and animals. The LPS induces inflammation by interacting with robust cellular mechanism which was considered as a plethora of numerous reproductive disorders such as fetal resorption, preterm birth, teratogenicity, intrauterine growth restriction, abortion, neural tube defects, fetal demise, and skeletal development retardation. LPS-triggered overproduction of free radicals leads to oxidative stress which mediates inflammation via stimulation of NF- $\kappa \mathrm{B}$ and PPAR $\gamma$ transcription factors. Flavonoids, which exist in copious amounts in nature, possess a wide array of functions; their supplementation during pregnancy activates Nrf2 signaling pathway which encounters pregnancy disorders. It was further presumed that the development of strong antioxidant uterine environment during gestation can alleviate diseases which appear at adult stages. The purpose of this review is to focus on modulatory properties of flavonoids on oxidative stress-mediated pregnancy insult and abnormal outcomes and role of Nrf2 activation in pregnancy disorders. These findings would be helpful for providing new insights in ameliorating oxidative stress-induced pregnancy disorders.

\section{LPS Overview and Its Drawbacks}

Early pregnancy failure is a main obstacle that leads to significant effects on pregnancy outcomes in humans and animals [1]. Approximately $15-20 \%$ clinical pregnancies experience abortion [2], and about $30-50 \%$ conception resulted in early embryonic loss in mammals [3]. Moreover, assisted reproductive techniques enhance pregnancy rate in infertile women without avoiding early embryonic loss [4]. Humans get constant exposure of LPS at minimum levels in gastrointestinal inflammatory diseases [5]. Lipopolysaccharide (LPS) is derived from G-negative bacteria; maternal exposure to pregnant rodents causes placental inflammation contributing in embryonic resorption, fetal growth restriction (FGR), preeclampsia fetal brain injury, and miscarriages which develops by alternation in cytokine productions $[6,7]$. These cytokines were released by trophoblastic, decidual, and chorioamnionitic cells and other cell types [8]. In humans, LPS infection provokes fetal loss and preterm labor [9] and is thought to be regulated by LPS-induced ROS-mediated 


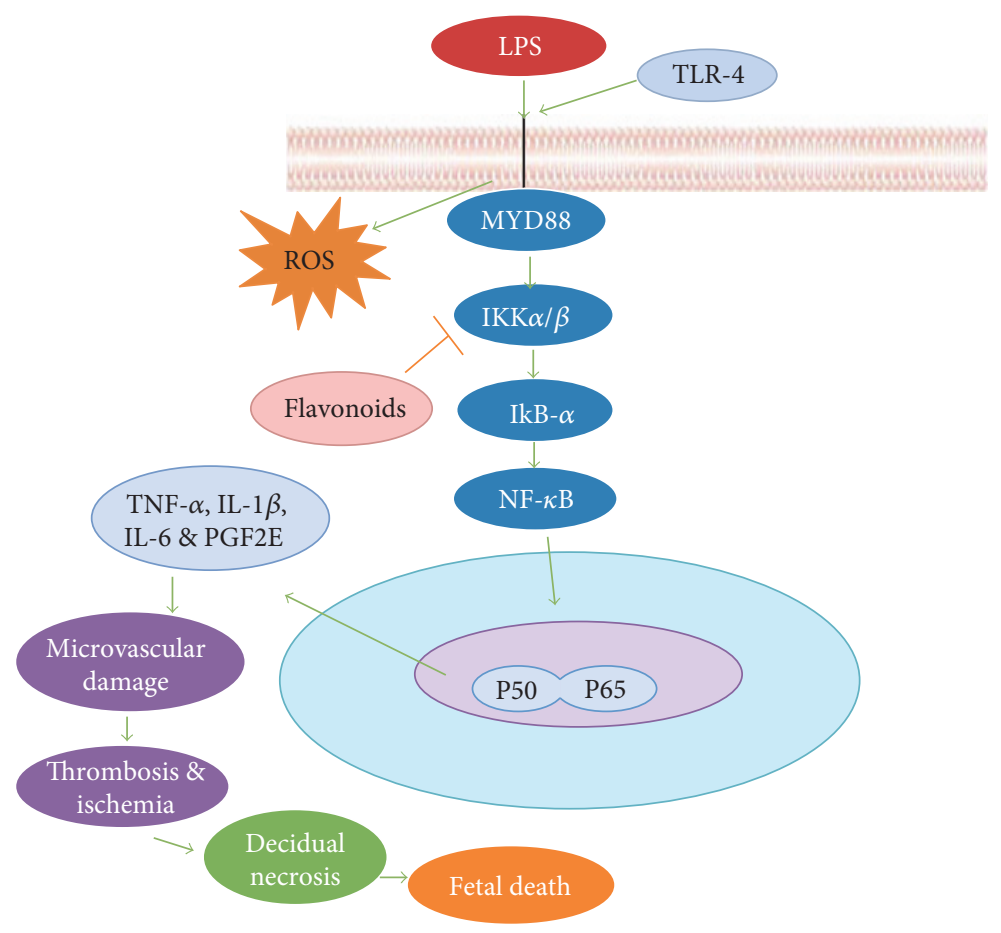

FIgURE 1: LPS-induced abortion by regulating strong cellular network. After induction of LPS, binding protein interacts with Toll-like receptor 4 (TLR4) and activates downstream adaptor proteins MYD-88, which subsequently stimulate IKK complex, resulting in ubiquitination and phosphorylation of $\mathrm{IkB} \alpha$ proteins that translocate NF- $\kappa \mathrm{B}$ into the nucleus for production of several proinflammatory cytokines such as TNF- $\alpha$, IL- $\beta$, IL-6, and PGF2E which causes microvascular damage leading to thrombosis, ischemia, necrosis of decidual cells, and finally abortion. On the other hand, flavonoids prevent abortion by inhibition of IKK complex proteins and bring NF- $\kappa \mathrm{B}$ into its inactivated form in cytoplasm. These beneficial effects of flavonoids are mediated by activation of PI3K/Akt pathway; hence, it prevents development of free radicals by supplementation of flavonoids during pregnancy.

teratogenesis [10]. In addition, basal amount of ROS is necessary in early embryonic growth and metabolism; excessive generation of uterine ROS is detrimental to oxidative DNA damage of the embryo [11, 12]. In pregnant mice, LPS exposure at late gestation leads to preterm delivery and fetal demise $[13,14]$, and in later gestational stages, maternal LPS infection causes intrauterine fetal growth restriction [15]. The signaling molecule, nitric oxide (NO), displays an essential role in implantation, decidualization, vasodilation, myometrial relaxation, and overactivation possibly induced by free radical-mediated pathology. Enhanced production of LPS-induced nitric oxide has been reported in embryonic resorption and abortion [16]. LPS-triggered abortion mechanism has been depicted in Figure 1. Nrf2 proteins display a key role in the elimination of oxidative stress through Nrf2-ARE signaling pathway $[17,18]$ as reported in preeclampsia conditions [19]. Nrf2 is very sensitive to maternal immune status and is responsible for fetal growth and survival through maintaining fetus desirable placental environment; later, Nrf2 protein expression of the placenta was decreased following delivery [20] suggesting its important function in fetal survival. Thus, any inappropriate function could lead to inducing numerous pregnancy disorders. The flavonoids of the polyphenol group are well-recognized natural compounds, which elicit strong antioxidant and anti-inflammatory activities that would be helpful in the elimination of LPS-potentiated pregnancy disorders. The polyphenols such as curcumin possess strong antiinflammatory activity through influencing diverse pathways to modulate cellular functions. It can also decrease inflammation by inhibiting NF- $\kappa \mathrm{B}$ pathway via inactivation of IKK complexes $[21,22]$. A study reported that curcumin polyphenols suppress methylglyoxal-induced apoptosis in mouse ESC-B5 cells and blastocysts by inhibiting reactive oxygen species (ROS) [23]. The anti-inflammatory strategy would be helpful in alleviating pregnancy-related complications [24]. This review emphasizes LPS-mediated pregnancy disorders and adverse birth outcomes, modulatory activities of polyphenols, and the role of Nrf2 signaling pathway. We have given detailed description below on the previous reports of polyphenol supplementations such as epigallocatechin gallate, curcumin, baicalin, and tricin which attenuate LPS-induced reproductive disorders, while genistein and quercetin develop strong antioxidant pregnant uterine environment that encounters disease in extrauterine life. These findings would be helpful in improving animal productions.

1.1. Disruption Pregnant Uterine Environment by Inflammatory Cytokines. The LPS binds with Toll-like receptor 4 (TLR4) with the facilitation of cluster of differentiation 14 (CD14) on cell surface of macrophages and monocytes. 
Upon activation of TLR4, it disseminates LPS signals to myeloid differentiation factor (MYD88) adaptor molecules; thus, its stimulation is known to be regulated by several signaling molecules including NF- $\kappa$ B proteins [25]. NF- $\kappa$ B exerts an important role in the development of inflammation while its activation occurs by degradation and phosphorylation of $\mathrm{I} \kappa \mathrm{B}$ kinases such as IKK $\alpha$ and IKK $\beta$ which results in the translocation of NF- $\kappa \mathrm{B}$ into the nucleus where it induces the formation of inflammatory cytokines, tumor necrosis factor- $\alpha$ (TNF- $\alpha$ ), interleukin-beta (IL-1 $\beta$ ), interleukin-6 (IL-6), and interleukin-8 (IL-8), and inducible inflammatory enzymes, nitric oxide (NO) and reactive oxygen species (ROS) $[26,27]$. As mentioned above, that LPS persuades inflammation which triggered various pregnancy disorders in mid and late gestation [28]. The inflammatory mediators, such as TNF- $\alpha$, interrupt placental blood supply and its function [29] resulting in fetal injury [30]. Studies on mice report that inflammation mediated by TNF- $\alpha$ and interferon-gamma (IFN $\gamma$ ) in macrophages and uterine natural killer (uNK) cells causes vascular injury and placental ischemia in uterine endothelial cells [31]. It was further noted that LPS mediates IFN $\gamma$ and TNF- $\alpha$ through activation of Toll-like receptors and is responsible for activation of cytokine-induced abortion [32] by possibly downregulating expression of cyclooxygenase-2 enzyme (COX-2) protein that encounters fibrinogen-like protein-2 (Fgl2) in the fetomaternal site [33]. The abortogenic effect varies according to the nature of LPS, source, time length, and dose regimen [32]. The interleukin-10 (IL-10) is an antiinflammatory cytokine which minimizes pregnancy-related inflammation through regulation of TNF- $\alpha$ and other cytokines and chemokines [34]. The growing body of texture revealed that maternal LPS induced uterine inflammation by cytokines through transplacental transmission that enhances the risk of brain diseases at the adult stage of life [35].

The peroxisome proliferator-activated receptor (PPAR) is a nuclear protein stimulated by multiple ways such as activations of prostaglandins (PGs) and leukotrienes (LTs). After activation, it stimulates transcription factors and mediates various cellular functions including cell differentiation, apoptosis, lipid metabolism, peroxisome proliferation, and inflammation response. In pregnancy, PPAR signals regulate trophoblast invasion and differentiation [36], placentation [37], and maternal metabolism [38]. The improper regulation of PPAR receptors causes complications including preeclampsia (PE), intrauterine growth restriction (IUGR), and preterm birth [39]. In vitro studies on knockout mice propose that stimulation of PPAR suppresses proinflammatory cytokines and distinguishes immune cells from anti-inflammatory phenotypes [40]. Naturally occurring compounds polyphenols exert ability to stimulate PPAR nuclear receptors and exert fruitful impact on pregnancy. It has been noted that PPAR $\gamma$ was considered as a potential target for therapeutic intervention against preeclampsia [41]. Limited research on PPAR signals in pregnancy disorders have been observed; therefore, more studies are needed to explore further insights.

\section{Positive Effects of Cytokines in Pregnancy Development}

Naturally, the immune system protects uterine environment from invading pathogens to full-term birth [42]. Excessive levels of endometrial cytokines, prostaglandins, and leukocytes are released during inflammatory condition [43]. The endometrial mediated cytokine and chemokine productions give directions to the blastocyst to connect with endometrial walls. When invasion and lysis of trophoblast exist, conversion from epithelial cells to stromal cells repairs endometrial tissue which replaces cells in the placenta. This structure is mediated by Th1 cellular responses where an ample amount of proinflammatory molecules such as IL-6, LIF, IL-8, and TNF- $\alpha$ was contributed [44] and these also recruit immune cells towards the decidua. In human and mouse, a huge population of decidual leukocytes has been witnessed at the site of implantation. Of note, these cells are comprised of $65-70 \%$ uterine natural killer (uNK) cells and $10-20 \%$, based on macrophages and dendritic cells (DCs) [45]. The macrophages and DCs localize in the decidua during the entire pregnancy and exhibit a key role at maternal-fetal interface [46]. The macrophages and DCs have the capability to secrete a variety of anti-inflammatory molecules (IL-4, IL-10, and IL-13) and enzymes, which are mainly involved in structural modification and angiogenesis [47]. Moreover, it was documented that macrophages mediate trophoblast invasion and might exert main function in eliminating debris which comes from trophoblastic apoptosis at different phases of gestation [44]. The presence of DCs in maternal tissue during implantation has been observed [48], and it was further illustrated that DCs have the ability to alter Th1 proinflammatory cytokines to Th2 anti-inflammatory cytokines at latter stages of gestation [49]. Near to parturition, anti-inflammatory response converted into pro-inflammatory response in order to induce uterine contractions initiates to parturition [50]. Overall, observation indicates the key functions of anti- to proinflammatory cytokine response during the entire pregnancy. Of note, limited evidences of inflammatory response have been documented before implantation of the embryo.

\section{Interruption in Redox Balance}

In normal homeostasis, ROS are neutralized by antioxidant defense in vivo. This balance is encountered by overpowering of ROS production and incompetency of antioxidant system to eliminate them. Growing evidences show that early exposure of oxidative stress in pregnancy might have long-term complications [51]. The antioxidant defense against locally produced NO by inducible nitric oxide synthase enzyme downregulates NO signals in the placenta which are crucially important for normal vascular development. In the first trimester of pregnancy, fetal growth was subjected to hypoxia [52], while in the prenatal period, it was documented that the fetus is highly vulnerable to oxidative damage whereas antioxidant supplementation during pregnancy ameliorates reproductive disorders such as implantation failure and fetal anomalies [53]. It has been reported that enhanced sodium dismutase-1 (SOD1) in mice suppresses fetal anomalies and 
protects against diabetes-related embryopathy [54]. In pregnancy, having intrauterine growth restriction (IUGR), preeclampsia (PE), and gestational diabetes mellitus (GDM) has been recorded to have higher chances of fetal hypoxia (markers of oxidative stress). Moreover, a deficient supply of oxygen has been observed in pathogenesis of IUGR and $\mathrm{PE}$ conditions [55]; on the other hand, preterm delivery arises from ischemia-reperfusion injury which decreased body weight.

\section{LPS-Driven Inflammatory Pathways}

LPS activates inflammation through multifaceted mechanism $[56,57]$ Maternal LPS triggers embryonic resorption through strong cellular network which is responsible for increased excessive placental TNF- $\alpha$, IL- $1 \beta$, and IL- 6 expressions that subsequently reduced phosphorylated Akt protein (serine/threonine-specific protein kinase) thereby causing decreased number of live pups, fetal weight, and placental weight $[6,58,59]$. Moreover, LPS also stimulates both transcription factors such as MAP kinases (MAPKs) and nuclear factor $-\kappa \mathrm{B}(\mathrm{NF}-\kappa \mathrm{B})$ [60]. Prevalence of uterine inflammation is a major outcome of infection and idiopathic preterm birth [61] caused by alleviation of cytokine activity before preterm labor, cervix and fetal membranes by neutrophils and macrophages [62]. Several studies reported that proinflammatory cytokines such as IL- $1 \beta$, IL- 6 , and TNF- $\alpha$ may activate contraction-associated proteins (CAPs) comprising oxytocin receptor (OTR), connexin 43 (CX43), prostaglandin $\mathrm{H}$ synthase- (PGHS-) 2, and prostaglandin receptors, in the myometrium, which exert uterotonic factors such as PGs that induce subsequently labor and inflammatory signals, suggesting a potential target in attenuating preterm birth [63]. In addition, normal labor in mouse associates with subsequent stimulation of $\mathrm{NF}-\kappa \mathrm{B}$ and $\mathrm{AP}-1$ within the uterus, whereas LPS-induced preterm labor (PTL) in two mouse models has been reported to have activated NF- $\kappa \mathrm{B}$ and Jun $\mathrm{N}$-terminal kinase (JNK) transcription factors [64].

\section{Pregnancy-Related Disorders and Adverse Birth Outcomes}

5.1. Effects of LPS on Decidual Cells. The vast literature has been published on decidual cells, which focuses on pregnancy recognition, fetal growth, and survival. Decidual cells are the maternal tissue which acts under the influence of progesterone and testosterone in circulation in order to maintain growth following implantation of blastocyst with the endometrium. Later on, decidual and trophoblastic cells form the placenta of maternal portion [65]. Crosstalk between LPS and Toll-like receptor 4 (TLR4) resulted in harmful effects on pregnancy through releasing a variety of inflammatory cytokines in murine models [66]. Certain cytokines such as IL-4, IL-6, and IL-10 elicit beneficial effects on pregnancy [67]. Wang et al. [68] demonstrated that baicalin treatment at $4 \mu \mathrm{g} / \mathrm{mL}$ to uterine decidual cells which was cultured with LPS on day 6 of pregnancy. Meanwhile, in in vivo experiment, LPS was inducted at day 6 of pregnancy and subjected on oral doses of baicalin at day 7 and day 8 of pregnancy.
The results documented that baicalin prevents damage to decidual cells and reduces TNF- $\alpha$ activity, hence producing fruitful effects on pregnant mice.

5.2. Maternal LPS-Mediated Teratogenicity. Some studies have found that LPS induces teratogenicity by overriding of free radicals. The subcut induction of LPS causes fetal malformation such as anencephaly and eye deformities [69] and developmental toxicity regulated by maternal side [70]. Uprising of tumor necrosis factor-alpha (TNF- $\alpha$ ) in fetal liver and brain-induced fetal death occurs through either maternal circulation or amniotic fluid which mediated LPS induction [71]. In addition, LPS also induced lipid peroxidation and GSH depletion in maternal liver and placenta and increases expression of $\mathrm{HO}-1$ in fetal liver that was counteracted by radical trapping agent $\mathrm{N}$-tertiary-butylnitrone $(\mathrm{PBN})$, a compound used for spin trapping. It has been well characterized that ROS are unstable reactive species which could not be eliminated successfully during organogenesis process and transfer from maternal to fetal tissues, irrespective of avoiding antioxidant defense. Hence, lacking of GSH proclaimed to develop ROS within fetal tissues. ROS developments in fetal tissues are not well clarified [72] though TNF- $\alpha$ can cross maternal serum and amniotic fluid to fetuses [71].

5.3. Oxidative Stress and Preterm Birth. Premature birth frequently occurs prior to normal delivery, when antioxidants could not be so active to alleviate oxidative stress resulting in preterm birth. It develops due to hindrance in uteroplacental transfer of nutrients which keeps newborns more sensitive against increasing ROS insults [73]. The MnSOD mRNA seems to be present in fetal membranes after labor and show its existence in chorioamnionitis [74]. It has been revealed that inflammation might be involved in placental antioxidant system which depends upon the concept development. Recently, studies rectified that $[75,76]$ cytokines are the main regulators for premature birth; hence, expression of NF- $\kappa \mathrm{B}$ induced cytokines as a novel target for alternative therapeutic options. NF- $\kappa \mathrm{B}$ is recognized in the induction of proinflammatory genes and mediates the expression of adhesion molecule, chemotactic factors, and acute phase proteins. The activation of NF- $\kappa$ B signaling pathway may enhance synthesis of proinflammatory cytokines that induce infected preterm birth $[77,78]$. The current study has shown that polyphenols particularly curcumin exert beneficial effects on inhibition of NF- $\kappa \mathrm{B}$-linked pregnant tissue-infected premature birth in mice, suppress TNF- $\alpha$ and IL- 8 , and mitigate oxidative insult in mothers and fetuses [79].

5.4. Preeclampsia and Oxidative Stress. Preeclampsia seems to be reported after 20 weeks of gestation in humans [80]. Some literatures build up strong relations between maternal inflammation and oxidative stress. Researchers stated that increased maternal inflammation through a variety of signaling pathways and presence of oxidative stress might be the possible factors for inducing preeclampsia condition $[81,82]$. In preeclampsia, reactive oxygen species initiates apoptosis of syncytiotrophoblast in placentation mechanism 
TABLE 1: Some enlisted Nrf2 gene regulation in maternofetal tissues.

\begin{tabular}{|c|c|c|c|}
\hline Origin & Regulation of Nrf2 protein/gene & Functional significance & References \\
\hline $\begin{array}{l}\text { Human umbilical } \\
\text { endothelial cells }\end{array}$ & NQO1, GCLM, Nrf2, GSK3 $\beta$ & $\begin{array}{l}\text { GDM } \uparrow \text { oxidative stress and } \downarrow \text { Nrf2 activity and } \\
\text { overexpression of antioxidant expression }\end{array}$ & [112] \\
\hline Rat & Nrf2, HO-1, SOD2 & $\begin{array}{c}\text { Hydroxytyrosol (HT) and moderate } \\
\text { Restraint stress (GD14-20) } \uparrow \text { Nrf2-dependent } \\
\text { gene expression }\end{array}$ & [113] \\
\hline Rat liver & GSTP, Nrf2 & $\begin{array}{l}\text { Maternal perfluorooctane sulfonate } \uparrow \text { methylation of Nrf2- } \\
\text { dependent GSTP gene promoter }\end{array}$ & [114] \\
\hline $\mathrm{Nrf} 2^{-/-}$and WT mice & $\begin{array}{l}\text { Nrf2, GSTA3, MGST1, GSTA4 } \\
\text { Gpx2, AKR1B1, AKR1B10, NQO1 }\end{array}$ & $\begin{array}{c}\text { Postnatal hyperoxia } \uparrow \mathrm{Nrf2} \text {-dependent gene expression, } \\
\text { abolished in } \mathrm{Nrf} 2^{-1-} \text { mice }\end{array}$ & [115] \\
\hline Mouse embryos & $\begin{array}{l}\text { Nrf2, SOD1, SOD2, SOD3, CAT, } \\
\text { Trx, Gpx1, Gpx2, Gpx3, GR }\end{array}$ & $\begin{array}{c}\text { Maternal ethanol or D3T exposure } \uparrow \mathrm{Nrf} 2 \text {-dependent } \\
\text { gene expression }\end{array}$ & [116] \\
\hline Mouse embryos & $\begin{array}{c}\text { GSH, NQO1, HO-1, GCLC, GST, Prx1 } \\
\text { Trx1, Trx2 }\end{array}$ & $\begin{array}{c}\text { Maternal D3T administration } \uparrow \text { Nrf2-dependent gene } \\
\text { and } \downarrow \mathrm{H} 2 \mathrm{O} 2 \text {-induced } \operatorname{Tr} x 1 \text { and } \operatorname{Tr} \times 2 \text { oxidation }\end{array}$ & {$[117]$} \\
\hline
\end{tabular}

AKR1B1: aldo-keto reductase family-1 member B1 (aldose reductase); AKR1B10: aldo-keto reductase family-10 member B10 (aldose reductase); CAT: Catalase); GCLC: glutamate-cysteine ligase catalytic subunit enzyme; GCLM: glutamate-cysteine ligase regulatory subunit enzyme; GDM: gestational diabetes mellitus; GR: glutathione reductase; GSK3 $\beta$ : glycogen synthase kinase 3 beta; GSH: glutathione peroxidase; GSTA3: glutathione S-transferase alpha-4; GSTA4: glutathione S-transferase alpha-4; Gpx1, 2, and 3: glutathione peroxidase 1, 2, and 3; GST: glutathione S-transferase; GSTP: glutathione reductase; GPO: glutathione peroxidase; HO-1: heme oxygenase; MGST1: microsomal glutathione S-transferase 1; NQO1: (NAD(P)H:quinone dehydrogenase 1; Nrf2: NF-E2-related factor 2; Prx1: peroxiredoxin 1; SOD1, 2, and 3: sodium dismutase 1, 2, and 3; Trx1 and 2: thioredoxin-1 and 2).

and affects anterior remodeling [83]; hence, it mediates inflammation. In addition, oxidative stress has been presumed to stimulate maternal endothelial cells as an inducer of preeclampsia condition [84].

5.5. Oxidative Stress-Induced IUGR Complications. Liu et al. [85] revealed that LPS induced intrauterine growth restriction in late gestation mice. It is stated that fetal IUGR is more susceptible in late gestation to increased risk of metabolic disorders such as insulin resistance, diabetes mellitus, obesity, hypertension, and cardiovascular diseases in model animals [86, 87]. Moreover, maternal protein restriction during pregnancy triggers fetal IUGR after prompt growth and alters gene expression in adipose tissue which is more prone to obesity in adult mice [88]. Numerous literatures established links of IUGR with oxidative stress. In IUGR pregnancies, oxidative stress markers such as MDA and protein oxidation of mother and fetus erythrocytes confirmed the strong relations [89]. In addition, oxidative/antioxidant markers were elevated in IUGR pregnancies, suggesting that neonates with IUGR elicited low level of antioxidant defense lipid peroxidation [90].

\section{Significant Impact of Nrf2 Pathway on Pregnancy}

Nrf2 is a leucine-based zipped transcription factor which displays a key role against oxidative stress by induction of phase II antioxidant enzymes [91]. Activation of Nrf2 is crucial for ameliorating oxidative stress-mediated cellular damage via protection through $20 \mathrm{~S}$ proteasome or [92] by p62-dependent autophagy [93]. Normally, Nrf2 is located in Kelch-like ECH-associated protein-1 (Keap1) [94]. Keap1 functions as sensors for oxidative stress [95]; upon activation, Nrf2 binds with Maf recognition/antioxidant response element and electrophilic response element (ARE/EpRE) in promoter target genes encompassing $\mathrm{NAD}(\mathrm{P}) \mathrm{H}$ :quinone oxireductase 1 (NQO1) [96], heme oxygenase1 (HO-1) [97], glutamate cysteine ligase(GCL) [98], and the light chain of the amino acid cystine-glutamate exchanger (xCT) [99] involved in glutathione biosynthesis. Notably, more than hundred genes have been identified; many of them are redox-sensitive transcription factors [100].

Numerous reports were described the protective effects of Nrf2 on the embryo against adverse effects of oxidative stress in utero (Table 1). Nrf2 knockout mice were considered as indicators of placental oxidative stress which suppress fetal growth [101]. Nrf2-deficient mice are vulnerable to methamphetamine-induced fetal DNA insult and neurological deficits [102], whereas polyphenols such as hydroxytyrosol-induced $\mathrm{Nrf} 2$ stimulation ameliorate oxidative stress-mediated effects in cognitive function and neurogenesis in offspring [103]. Activation of Nrf2 has exhibited to reduce Et-OH-induced neural crest apoptotic cells in a fetus [104], and trophoblastic triggered apoptosis by inflammation [105]. At the same time, aforementioned studies indicated that Nrf2 exerts protective effects towards oxidative insult during early-pregnancy development (i.e., neutral crest formation), while some other studies documented significant effects of $\mathrm{Nrf} 2$ in redox mechanism in later-developmental phases. The in utero Keap1/Nrf2 signals have been demonstrated in response to amniotic fluid through increased expressions of genes contributed in epidermal development [106]. The Nrf2 is very sensitive to the maternal immune system to mediate the function of fetal membranes to birth. Importantly, Nrf2 protein expression was decreased in fetal membranes during pregnancy due to amniotic infection. The pitfalls in Nrf2 regulation can facilitate preterm delivery; knockdown of $\mathrm{Nrf} 2$ in amniotic cells causes upregulations of proinflammatory cytokines which causes rupturing fetal membranes. Moreover, a beneficial effect of Nrf2 on antioxidant mechanism 
is more obvious in alleviating adverse developmental outcomes. In neural crest cells, where excessive glucose declines, CuZnSOD, MnSOD, catalase, GPx1, Nrf2, and Pax3 expressions induce vulnerability to these cells which leads to oxidative damage [107]. Importantly, overexpression of catalase enhances Nrf2 and its downstream HO-1 expression, thus showing a protecting role in obesity-induced diabetes fetal renal damage [108]. The Nrf2 expression is also decreased in IUGR placenta [109]. In preeclampsia pregnancies, the role of $\mathrm{Nrf} 2$ has been reported to be somehow controversial, whereas reduced expression of Nrf2 was noted in placental oxidative stress-induced preeclampsia [110]. Inappropriate regulation of Nrf2-based $\mathrm{HO}-1$ expression mediates soluble fms-like typrsine kinase-1 (sFlt-1) [111]. Increased level of sFtl-1 has been recorded in the pathogenesis of $\mathrm{PE}$ and development of maternal hypertensive condition during pregnancy. Overall, Nrf2 function in normal pregnancy is incomplete although it is providing protection during uterofetal life against a variety of stressors.

Cheng et al. [112] have demonstrated that protein levels were significantly affected during redox status of GDM due to overproduction of superoxide radicals, protein oxidation, DNA damage, and reduced GSH synthesis. Moreover, in GDM cells, lipid peroxidation did not show Nrf2 genes and protein levels to its targeted genes $\mathrm{NAD}(\mathrm{P}) \mathrm{H}$ :quinone oxidoreductase 1 (NQO1), Bach1, cystine/glutamate transporter, and glutamate cysteine ligase. Lipid peroxidation triggered GSH and NQO1 activity which was revoked by Nrf2 in normal cells, and overexpression of Nrf2 in GDM cells partly restored NQO1 induction. Improper functions of Nrf2 in fetal endothelium increased the risk of inducing T2DM and CVD diseases to offspring. Zheng et al. [113] revealed the alternation in spontaneous activity and impair in learning and memory levels in prenatal stress male and female offspring. The stress was found to be due to downregulating of neuronal proteins and glucocorticoid levels. Similarly, alteration in protein oxidation, SOD, and mitochondrial activity was also declined, whereas hydroxytyrosol (HT) enhanced FOXO1 and FOXO3, Nrf2, and $\mathrm{HO} 1$ proteins and restored mitochondrial functions. It indicates that HT is a potential maternal nutritive compound that provides protection towards neurogenesis and cognitive offspring. In a study documented by Wan et al. [114], exhibiting the overexpressions of GSTP was contributed with transcription factors Keap1-Nrf2/MafK. Therefore, early induced alternations in cytosines within GSTP gene were referred as a biomarker of hepatic PFOS, whereas the direct role of PFOS-induced hepatotoxicity needs to be further elucidated. In another findings demonstrated by [115], it was shown that hyperoxia induced alveolar growth in neonatal lung by induction of $\mathrm{p} 21 / \mathrm{p} 53$ pathways, a potential risk for developing bronchopulmonary dysplasia (BPD) in preterm infants. Results indicate that activation of $\mathrm{Nrf} 2$ pathway promoted antioxidant response genes which were declined by hyperoxia. Dong et al. [116] reported that exposure of maternal ethanol induces fetal alcohol syndrome that enhanced expression of Nrf2 and Nrf2-ARE protein levels in mouse embryos. Hence, it increases the response of proteins and antioxidant enzymes. In addition, dithiole-3-thione (D3T) treatment minimizes ethanol-mediated reactive oxygen species productions and inhibits apoptosis in mouse embryos. The results reported that simulation of Nrf2 was involved in releasing antioxidant response against exposure of ethanol embryos. In other investigation, it was documented that $\mathrm{H}_{2} \mathrm{O}_{2}$ decreased glutathione peroxidase ( $\mathrm{GSH}$ ), thioredoxin-1 (Trx1), and mitochondrial thioredoxin-2 (Trx2) in a whole cultured embryo with $10 \mu \mathrm{M}$ dithiole-3thione (D3T). D3T enhanced Nrf2 responsive genes. These findings showed that stimulation of Nrf2 provides protection against chemically mediated oxidative stress by maintaining intracellular redox mechanism, thereby stabilizing normal embryo development [117].

\section{Dietary Supplementation of Polyphenols during Pregnancy}

Flavonoids, the compounds of polyphenols, have received worldwide recognition due to their enormous existence in nature, and more than 10000 diverse molecular components have been identified so far [118]. Foods, vegetables, fruits, and herbs are rich sources of flavonoids [119]. It has come into central position due to presenting several functions encompassing antioxidant, anti-inflammatory, and antiabortogenic properties [120, 121]. LPS mediates inflammation through numerous series of cellular events that subsequently stimulates NF- $\kappa \mathrm{B}$ pathway which encodes genes for inducing inflammation such as iNOS, NO, and COXs that synthesize prostaglandins and cytokines. Moreover, Toll-like receptors are responsible for the production of reactive oxygen species [122, 123]. As described above, LPS mediates pregnancy disorders and adverse birth outcomes through the regulation of proinflammatory cytokines such as TNF- $\alpha$ and IL- 8 in maternal sera, amniotic fluid, fetal liver and fetal brain [124] and induced fetal IUGR, fetal resorption, and preterm delivery which was reversed by TNF- $\alpha$ inhibitor and chemokine inhibitor, respectively. Flavonoids suppress chemokine production comprising TNF- $\alpha$, IL- $1 \beta$, and monocyte chemoattractant protein-1 [125]; some protective effects of polyphenols are illustrated in Table 2.

The uptake of enriched polyphenol food has been documented to enhance plasma antioxidant status in humans [126] and reduce incidences of oxidative insult in vitro and in vivo studies in a human placenta and trophoblasts, respectively [127]. The flavonoids ameliorate oxidative stress-mediated inflammatory response by suppression of inflammatory mediators (reactive oxygen species (ROS) and nitric oxide (NO)), decreased inflammatory enzymes such as cyclooxygenases (COXs) and inducible nitric oxide synthase (iNOS) modulating NF- $\kappa \mathrm{B}$ and activating protein1 (AP-1) signals $[26,128]$ decreasing cytokine expressions, and activation of phase II enzymes glutathione S-transferase (GST) [129]. Supplementation of polyphenols has shown beneficial effects on pregnancy and was referred as therapeutic intervention to encounter pregnancy disorders and adverse birth outcomes [130]. Lack of antioxidant defense creates hindrances in homeostasis due to the exceeding amount of ROS, while their supplementation may show protective effects [130]. 
TABLE 2: Beneficial effects of polyphenols in LPS-induced pregnancy disorders.

\begin{tabular}{|c|c|c|c|c|}
\hline LPS doses & $\begin{array}{c}\text { Gestation stages } \\
\text { (days) }\end{array}$ & Pregnancy disorders & Flavonoids/protective effects & References \\
\hline LPS $0.2 \mathrm{~mL} / 0.2 \mu \mathrm{g} / \mathrm{mouse}$ & $4-7$ & Abortion & $\begin{array}{c}\text { Quercetin indicates antiabortive effects through } \\
\text { influence on CD4+/CD8+ T lymphocytes } \\
\text { and IFN and IL-4 }\end{array}$ & [136] \\
\hline LPS $0.1 \mu \mathrm{g}$ per mouse & 6.7 & Fetal resorption & $\begin{array}{l}\text { Polyphenolic compounds of Radix Scutellariae and } \\
\text { Rhizoma Atractylodis (baicalein, wogonin, oroxylin, } \\
\text { baicalin, wogonoside, oroxylin A-7-glucuronide } \\
\text { reduced fetal resorption and including IL-10 } \\
\text { Pharmacological effects and pharmacokinetic properties } \\
\text { of Radix Scutellariae and its bioactive flavones }\end{array}$ & {$[137,138]$} \\
\hline $\begin{array}{l}\mathrm{LPS}, 0.1 \mathrm{~mL} / 10 \mathrm{~g} \\
\text { in vitro/in vivo }\end{array}$ & $\begin{array}{l}6 \\
6 \& 7\end{array}$ & Injury of decidual cells & $\begin{array}{l}\text { Baicalin, } 4 \mu \mathrm{g} / \mathrm{mL} \text { in vitro and in vivo at different doses } \\
\text { prevents decidual cell injury by inhibition of TNF- } \alpha\end{array}$ & {$[68]$} \\
\hline $\begin{array}{l}\text { LPS at } 0.2 \mathrm{ml} \text {, } \\
\text { murine model }\end{array}$ & 7 & $\begin{array}{l}\text { Abortion and } \\
\text { reabsorption }\end{array}$ & $\begin{array}{c}\text { Bao Tai Wu You, Tai Shan Pan Shi, or Bai Zhu San } \\
\text { at } 0.5 \mathrm{ml} \text { oral medication for } 7 \text { days ameliorates } \\
\text { INF- } \gamma \text { and increases IL-10 and IL- } 4 \text { thus showing } \\
\text { beneficial effects }\end{array}$ & [139] \\
\hline
\end{tabular}

CD4 and 8: cluster of differentiation 4 and 8; IFN: interferon; IL-4: interleukine-4; IL-10: interleukine-10; INF- $\gamma$ : interferon gamma; TNF- $\alpha$ : tumor necrosis factor-alpha.

Vanhees et al. [131] exhibited that exposure to intrauterine flavonoids such as quercetin and genistein at lower level inhibited oxidative stress and DNA damage in the liver of adult mice that subsequently develops antioxidant environment through regulation of $\mathrm{Nrf} 2$ signaling pathway. It indicates that dietary antioxidant supplementation during gestation develops long lasting antioxidant defense that eliminate oxidative stress at adulthood, where oxidative stress was assumed to be involved in chronic diseases. Importantly, LPS-mediated inflammation plays a key role in embryonic resorption, fetal growth restriction, and preeclampsia [132]. The polyphenols like curcumin ameliorate abnormal pregnancy outcomes by suppressed LPS-triggered inflammation in mice. The anti-inflammation activity of curcumin was achieved by upregulation of phosphorylated Akt pathway which was decreased by LPS induction [59]. Tricin, a polyphenol-derived compound, encountered inflammation by activation of Akt signals and cellular proliferation. This anti-inflammatory effect of Akt pathway was obtained by inhibition of IKK protein activity which brings NF- $\kappa$ B back into the cytoplasm in its normal physiological position [133]. Several compounds like the flavonoid group of polyphenols induced stimulation of Nrf2 signals. This evidence was proved by [134] who revealed the neuroprotective properties of polyphenols by activation of $\mathrm{Nrf} 2 / \mathrm{HO}-1$, thereby exerting therapeutic insights of polyphenolic compounds. Another example of epigallocatechin gallate (EGCG) treatment enhanced nuclear accumulation, anti-oxidant response element (ARE) binding with Nrf2.These results indicated that ECGC regulated Nrf2-mediated expression of few antioxidant enzymes particularly stimulation of Akt and ERK1/2 signaling; hence, it supports antioxidant system in attenuating oxidative stress [135]. Some polyphenols and their chemical structure are depicted in Figure 2. Literature has shown a less number of studies on antioxidant supplementation such as flavonoids during pregnancy, as it was known as strong antioxidative compounds proven from other evidence, whereas some report exhibited ambiguous results that might be due to timing of supplementation, improper dose regimen, and lack of antioxidant-targeted compounds. More research should be warranted to explore methods for minimizing uterine oxidative stress and mimic ROS-mediated diseases from mothers to newborns.

\section{Concluding Remarks and Future Perspectives}

We have clearly defined that stimulation of Toll-like receptors by LPS-induced generation of free radicals and their excessive amount leads to fetal resorption, preterm birth, teratogenicity, intrauterine growth restriction, abortion, neural tube defects, fetal demise, and skeletal development retardation. Moreover, oxidative stress also activates $\mathrm{NF}-\kappa \mathrm{B}$, PPAR- $\gamma$, AP-1, and JNK pathways which accounts for pathological conditions in aforementioned pregnancy disorders. In addition, NF- $\kappa \mathrm{B}$ is responsible for transcription of several proinflammatory cytokines which are known to induce pregnancy disorders and adverse outcomes such as TNF- $\alpha$, IL- $1 \beta$, IL-6, and PGF2E. Importantly, stimulation of Nrf2 signals plays a crucial role in ameliorating pregnancy insults. It was further counted that oxidative stress is the major contributing factor, whereas polyphenols are the novel compounds for treating oxidative stress-related disorders. Limited studies have been documented on polyphenol supplementation during pregnancy and its outcomes. It was presumed that intrauterine fetal life decides the future of a wide array of complications which appear at later stages of life. Nutrition and antioxidant supplement are the main players for fetal reprogramming. Any impairment in this system might have disturbance in extrauterine life. Studies reported that strong maternal uterine antioxidant environment could prevent pregnancy disorders and abnormal birth outcomes and could also prevent other complications later in life which might initiate from embryonic stage. More molecular evidences are required for antioxidant/inflammatory events from 
<smiles>COc1cc(C2=CC(O)c3c(O)cc(O)cc3O2)cc(OC)c1O</smiles><smiles></smiles>

Epigallocatechin gallate<smiles>O=C(O)[C@H]1O[C@@H]2Oc3cc4oc(-c5ccccc5)cc(=O)c4c(O)c3O[C@H](O)[C@@H](O)[C@H](O)[C@H]2O1</smiles><smiles>COc1cc(/C=C/C(=O)/C=C(O)/C=C/c2ccc(O)c(OC)c2)ccc1O</smiles><smiles>COc1cc(/C=C/C(=O)CC(=O)/C=C/c2ccc(O)c(OC)c2)ccc1O</smiles>

Baicalin

Curcumin<smiles>O=c1c(-c2ccc(O)cc2)coc2cc(O)cc(O)c12</smiles>

Genistein<smiles>OCCc1ccc(O)c(O)c1</smiles>

Hydroxytyrosol<smiles>OCCc1ccc(O)cc1</smiles>

Tyrosol

FIGURE 2: Some polyphenol compounds and their chemical structures.

fertilization to parturition during pregnancy. We assume that these findings would be helpful in understanding oxidative stress-induced pregnancy insults and might give new roadmap to researchers for therapeutic intervention which could subsequently improve human and animal fertility.

\section{Abbreviations}

Akt:

AP-1:

CAPs:

CD14:

COX-2:

CX43:

EGCG:

ERK1/2:

ESC-B5:
Serine/threonine-specific protein kinase Activated protein kinase-1

Contraction-associated proteins

Cluster of differentiation 14

Cyclooxygenases- 2

Connexin 43

Epigallocatechin-3-gallate

Extracellular signal-regulated kinase 1/2

Embryonic stem cell B5
FGR: $\quad$ Fetal growth rate

FOXO1 and 3: Forkhead box protein $\mathrm{O} 1$ and 3

GCL: Glutamate cysteine ligase

GDM: Gestational diabetes mellitus

GST: Glutathione S-transferase

HO-1: Heme oxygenase1

IFN $\gamma$ : Interferon- $\gamma$

iNOS: $\quad$ Inducible nitric oxide synthase

IUGR: Intrauterine growth restriction

JNK: Jun N-terminal kinase transcription factors

LPS: $\quad$ Lipopolysaccharides

MAPKs: $\quad$ Mitogen-activated protein kinases

MDA: $\quad$ Malondialdehyde

MYD88: $\quad$ Myeloid differentiation factor

NF- $\kappa$ B: $\quad$ Nuclear factor kappa B

Nrf2: $\quad$ NF-E2-related factor 2

OTR: Oxytocin receptor 


$\begin{array}{ll}\text { NO: } & \text { Nitric oxide } \\ \text { PE: } & \text { Preeclampsia } \\ \text { PGs: } & \text { Prostaglandins } \\ \text { PGHS: } & \text { Prostaglandin H synthase } \\ \text { PPAR } \gamma: & \text { Peroxisome proliferator-activated receptor } \\ & \text { gamma } \\ \text { ROS: } & \text { Reactive oxygen species } \\ \text { sFlt-1: } & \text { Soluble fms-like typrsine kinase-1 } \\ \text { SOD1: } & \text { Sodium dismutase-1 } \\ \text { TNF- } \alpha: & \text { Tumor necrosis factor- } \alpha \\ \text { uNK: } & \text { Uterine natural killer } \\ \text { xCT: } & \text { Cystine-glutamate exchanger. }\end{array}$

\section{Conflicts of Interest}

The authors declare not any conflict of interest.

\section{Acknowledgments}

This project was funded by the National Natural Science Foundation of China $(31330075,31372326,31672433$, and 31560640), Key Programs of frontier scientific research of the Chinese Academy of Sciences (QYZDY-SSW-SMC008), and Youth Innovation Team Project of ISA, CAS (2017QNCXTD_TBE). The authors are thankful to CASTWAS President's Fellowship and the financial and infrastructure support from UCAS, as well as Changsha Lvye Biotechnology Limited Company Academician Expert Workstation.

\section{References}

[1] X. F. Zeng, F. Wang, X. Fan et al., "Dietary arginine supplementation during early pregnancy enhances embryonic survival in rats," Journal of Nutrition, vol. 138, pp. 1421-1425, 2008.

[2] K. McNamee, F. Dawood, and R. Farquharson, "Recurrent miscarriage and thrombophilia: an update," Current Opinion in Obstetrics and Gynecology, vol. 24, no. 4, pp. 229-234, 2012.

[3] A. K. Goff, "Embryonic signals and survival," Reproduction Domestic Animals, vol. 37, no. 1, pp. 133-139, 2002.

[4] D. D. Neubourg, J. Gerris, K. Mangelschots, E. Van Royen, M. Vercruyssen, and M. Elseviers, "Single top quality embryo transfer as a model for prediction of early pregnancy outcome," Human Reproduction, vol. 19, pp. 1476-1479, 2004.

[5] Z. Zhou, L. Wang, Z. Song, J. C. Lambert, C. J. McClain, and Y. J. Kang, "A critical involvement of oxidative stress in acute alcohol-induced hepatic TNF-alpha production," American Journal of Pathology, vol. 163, pp. 1137-1146, 2003.

[6] A. Kunnen, M. G. van Pampus, J. G. Aarnoudse, C. P. van der Schans, F. Abbas, and M. M. Faas, "The effect of Porphyromonas gingivalis lipopolysaccharide on pregnancy in the rat," Oral Diseases, vol. 20, no. 6, pp. 591-601, 2014.

[7] P. Xue, M. Zheng, P. Gong et al., "Single administration of ultra-low-dose lipopolysaccharide in rat early pregnancy induces TLR4 activation in the placenta contributing to preeclampsia," PLoS One, vol. 10, no. 4, article e0124001, 2015.
[8] J. M. Bowen, L. Chamley, M. D. Mitchell, and J. A. Keelan, "Cytokines of the placenta and extraplacental membranes: biosynthesis, secretion and roles in establishment of pregnancy in women," Placenta, vol. 23, pp. 239-256, 2002.

[9] S. Collins, M. Ramsay, M. P. Slack et al., "Risk of invasive Haemophilus influenzae infection during pregnancy and association with adverse fetal outcomes," The Journal of the American Medical Association, vol. 311, no. 11, pp. 11251132, 2014.

[10] D. X. Xu, H. Wang, H. Ning, L. Zhao, and Y. H. Chen, "Maternally administered melatonin differentially regulates lipopolysaccharide-induced proinflammatory and antiinflammatory cytokines in maternal serum, amniotic fluid, fetal liver, and fetal brain," Journal of Pineal Research, vol. 43, pp. 74-79, 2007.

[11] A. Ornoy, "Embryonic oxidative stress as a mechanism of teratogenesis with special emphasis on diabetic embryopathy," Reproductive Toxicology, vol. 24, pp. 31-41, 2007.

[12] P. G. Wells, G. P. McCallum, K. C. Lam, J. T. Henderson, and S. L. Ondovcik, "Oxidative DNA damage and repair in teratogenesis and neurodevelopmental deficits," Birth Defects Research Part C, Embryo Today, vol. 90, pp. 103-109, 2010.

[13] I. A. Buhimschi, C. S. Buhimschi, and C. P. Weiner, "Protective effect of $\mathrm{N}$-acetylcysteine against fetal death and preterm labor induced by maternal inflammation," American Journal of Obstetrics \& Gynecology, vol. 188, pp. 203-208, 2003.

[14] Y. Zhao, K. Koga, Y. Osuga et al., "Cyclic stretch augments production of neutrophil chemokines and matrix metalloproteinase-1 in human uterine smooth muscle cells," American Journal of Reproductive Immunology, vol. 69, pp. 240-247, 2013.

[15] D. L. Rivera, S. M. Olister, X. Liu et al., "Interleukin-10 attenuates experimental fetal growth restriction and demise," Federation of American Societies of Experimental Biology Journal, vol. 12, pp. 189-197, 1998.

[16] D. G. Ogando, D. Paz, M. Cella, and A. M. Franchi, "The fundamental role of increased production of nitric oxide in lipopolysaccharide-induced embryonic resorption in mice," Reproduction, vol. 125, pp. 95-110, 2003.

[17] S. J. Chapple, R. C. Siow, and G. E. Mann, "Crosstalk between $\mathrm{Nrf2}$ and the proteasome: therapeutic potential of Nrf2 inducers in vascular disease and aging," International Journal of Biochemistry and Cell Biology, vol. 44, pp. 1315-1320, 2012.

[18] R. Howden, "Nrf2 and cardiovascular defense," Oxidative Medicine and Cellular Longevity, vol. 2013, Article ID 104308, 10 pages, 2013.

[19] N. Kweider, A. Fragoulis, C. Rosen et al., "Interplay between vascular endothelial growth factor (VEGF) and nuclear factor erythroid 2-related factor-2 (Nrf2): implications for preeclampsia," The Journal of Biological Chemistry, vol. 286, pp. 42863-42872, 2011.

[20] R. Lim, G. Barker, and M. Lappas, "The transcription factor $\mathrm{Nrf2}$ is decreased after spontaneous term labour in human fetal membranes where it exerts anti-inflammatory properties," Placenta, vol. 36, pp. 7-17, 2015.

[21] Y. Gan, S. Zheng, J. P. Baak et al., "Prediction of the antiinflammatory mechanisms of curcumin by module-based protein interaction network analysis," Acta Pharmaceutica Sinica-B, vol. 5, no. 6, pp. 590-595, 2015. 
[22] B. Rajitha, A. Belalcazar, G. P. Nagaraju et al., "Inhibition of NF-KB translocation by curcumin analogs induces G0/G1 arrest and downregulates thymidylate synthase in colorectal cancer," Cancer Letters, vol. 373, no. 2, pp. 227-233, 2016.

[23] Y. D. Hsuuw, C. K. Chang, W. H. Chan, and J. S. Yu, "Curcumin prevents methylglyoxal-induced oxidative stress and apoptosis in mouse embryonic stem cells and blastocysts," Journal of Cellular Physiology, vol. 205, no. 3, pp. 379-386, 2005.

[24] D. Barrera, L. Díaz, N. Noyola-Martínez, and A. Halhali, "Vitamin D and inflammatory cytokines in healthy and preeclamptic pregnancies," Nutrients, vol. 7, no. 8, pp. 64656490, 2015.

[25] L. Verstrepen, T. Bekaert, T. L. Chau, J. Tavernier, A. Chariot, and R. Beyaert, "TLR-4, IL-1R and TNF-R signaling to NFkappaB: variations on a common theme. Cellular and molecular life sciences," Cellular and Molecular Life Sciences, vol. 65, no. 19, pp. 2964-2978, 2008.

[26] D. Ribeiro, M. Freitas, J. L. Lima, and E. Fernandes, "Proinflammatory pathways: the modulation by flavonoids," Medicinal Research Review, vol. 35, no. 5, pp. 877-936, 2015.

[27] E. Bognár, The critical role of MAP-kinases and PI3KAkt signaling pathways in inflammation and oxidative stress, [Ph.D. Thesis], University of Pécs, Medical School Department of Biochemistry and Medical Chemistry, Hungary, 2013.

[28] M. Zhao, Y. H. Chen, X. Chen et al., "Folic acid supplementation during pregnancy protects against lipopolysaccharideinduced neural tube defects in mice," Toxicology Letters, vol. 224, pp. 201-208, 2014.

[29] J. Yui, M. Garcia-Lloret, T. G. Wegmann, and L. I. Guilbert, "Cytotoxicity of tumour necrosis factor-alpha and gammainterferon against primary human placental trophoblasts," Placenta, vol. 15, no. 8, pp. 819-835, 1994.

[30] O. Dammann and A. Leviton, "Maternal intrauterine infection, cytokines, and brain damage in the preterm newborn," Pediatric Research, vol. 42, pp. 1-8, 1997.

[31] D. A. Clark, G. Chaouat, P. C. Arck, H. W. Mittruecker, and G. A. Levy, "Cutting edge: ctokine-dependent abortion in $\mathrm{CBA} \times \mathrm{DBA} / 2$ mice is mediated by the procoagulant fgl2 prothombinase," The Journal of Immunology, vol. 160, no. 2, pp. 545-549, 1998.

[32] D. A. Clark, G. Yu, P. C. Arck, G. A. Levy, and R. M. Gorczynski, "MD-1 is a critical part of the mechanism causing Th1-cytokine-triggered murine fetal loss syndrome," American Journal of Reproductive Immunology, vol. 49, pp. 297-307, 2003.

[33] D. A. Clark, J. W. Ding, G. Yu, G. A. Levy, and R. M. Gorczynski, "Fgl2 prothrombinase expression in mouse trophoblast and decidua triggers abortion but may be countered by OX-2," Molecular Human Reproduction, vol. 7, pp. 185-194, 2001.

[34] K. W. Moore, R. de Waal Malefyt, R. L. Coffman, and A. O'Garra, "Interleukin-10 and the interleukin-10 receptor," Annual Reviews in Immunology, vol. 19, pp. 683-765, 2001.

[35] M. F. Miller and R. Loch-Caruso, "Comparison of LPSstimulated release of cytokines in punch versus transwell tissue culture systems of human gestational membranes," Reproductive Biology and Endocrinology, vol. 8, p. 121, 2010.

[36] W. T. Schaiff, M. G. Carlson, S. D. Smith, R. Levy, D. M. Nelson, and Y. Sadovsky, "Peroxisome proliferator-activated receptor-gamma modulates differentiation of human trophoblast in a ligand-specific manner," Journal of Clinical Endocrinology and Metabolism, vol. 85, pp. 3874-3881, 2000.

[37] Y. Barak, M. C. Nelson, E. S. Ong et al., "PPAR gamma is required for placental, cardiac, and adipose tissue development," Molecular Cell, vol. 4, pp. 585-595, 1999.

[38] L. L. Waite, E. C. Person, Y. Zhou, K. H. Lim, T. S. Scanlan, and R. N. Taylor, "Placental peroxisome proliferatoractivated receptor-gamma is up-regulated by pregnancy serum," Journal of Clinical Endocrinology \& Metabolism, vol. 85, pp. 3808-3814, 2000.

[39] F. Wieser, L. Waite, C. Depoix, and R. N. Taylor, "PPAR action in human placental development and pregnancy and its complications," PPAR Research, vol. 2008, Article ID 527048, 14 pages, 2008.

[40] H. Martin, "Role of PPAR-gamma in inflammation. Prospects for therapeutic intervention by food components," Mutation Research, vol. 690, no. 1-2, pp. 57-63, 2010.

[41] F. P. McCarthy, S. Drewlo, F. A. English et al., "Evidence implicating peroxisome proliferator-activated receptor- $\gamma$ in the pathogenesis of preeclampsia," Hypertension, vol. 58, pp. 882-887, 2011.

[42] G. Mor and I. Cardenas, "The immune system in pregnancy: a unique complexity," American Journal of Reproductive Immunology, vol. 63, pp. 425-433, 2010.

[43] R. W. Kelly, A. E. King, and H. O. Critchley, "Cytokine control in human endometrium," Reproduction, vol. 121, pp. 3-19, 2001.

[44] M. S. van Mourik, N. S. Macklon, and C. J. Heijnen, "Embryonic implantation: cytokines, adhesion molecules, and immune cells in establishing an implantation environment," Journal of Leukocyte Biology, vol. 85, no. 1, pp. 4-19, 2009.

[45] J. Hanna, D. Goldman-Wohl, Y. Hamani et al., "Decidual NK cells regulate key developmental processes at the human fetal-maternal interface," Natural Medicines, vol. 12, pp. 1065-1074, 2006.

[46] S. Fest, P. B. Aldo, V. M. Abrahams et al., "Trophoblastmacrophage interactions: a regulatory network for the protection of pregnancy," American Journal of Reproductive Immunology, vol. 57, pp. 55-66, 2007.

[47] Z. M. David Dong, A. C. Aplin, and R. F. Nicosia, "Regulation of angiogenesis by macrophages, dendritic cells, and circulating myelomonocytic cells," Current Pharmaceutical Desigen, vol. 15, no. 4, pp. 365-379, 2009.

[48] V. Plaks, T. Birnberg, T. Berkutzki et al., "Uterine DCs are crucial for decidua formation during embryo implantation in mice," Journal of Clinical Investigation, vol. 118, no. 12, pp. 3954-3965, 2008.

[49] T. Nagamatsu and D. J. Schust, "The immunomodulatory roles of macrophages at the maternal-fetal interface," Reproductive Sciences, vol. 17, no. 3, pp. 209-218, 2010.

[50] R. Romero, J. Espinoza, J. P. Kusanovic et al., "The preterm parturition syndrome," BJOG: An International Journal of Obstetrics and Gynecology, vol. 113, no. 3, pp. 17-42, 2006.

[51] A. Sola, M. R. Rogido, and R. Deulofeut, "Oxygen as a neonatal health hazard: call for detente in clinical practice," Acta Paediatrica, vol. 96, no. 6, pp. 801-812, 2007.

[52] G. Burton, H. W. Yung, T. Cindrova-Davies, and D. Charnock-Jones, "Placental endoplasmic reticulum stress and oxidative stress in the pathophysiology of unexplained 
intrauterine growth restriction and early onset preeclampsia," Placenta, vol. 30, pp. 43-48, 2009.

[53] J. G. Eriksson, T. Forsen, J. Tuomilehto, P. D. Winter, C. Osmond, and D. J. Barker, "Catch-up growth in childhood and death from coronary heart disease: longitudinal study," British Medical Journal, vol. 318, pp. 427-431, 1999.

[54] Z. J. Hagay, Y. Weiss, I. Zusman et al., "Prevention of diabetes-associated embryopathy by overexpression of the free radical scavenger copper zinc superoxide dismutase in transgenic mouse embryos," American Journal of Obstetrics, \& Gynecology, vol. 173, pp. 1036-1041, 1995.

[55] F. Lackman, V. Capewell, R. Gagnon, and B. Richardson, "Umbilical cord oxygen values and birth to placental weight ratio in relation to size at birth," American Journal of Obstetrics and Gynecology, vol. 185, pp. 674-682, 2011.

[56] J. M. Soos, P. S. Subramaniam, A. C. Hobeika, J. Schiffenbauer, and H. M. Johnson, "The IFN pregnancy recognition hormone IFN-tau blocks both development and superantigen reactivation of experimental allergic encephalomyelitis without associated toxicity," Journal of Immunology, vol. 155, pp. 2747-2753, 1995.

[57] H. C. Do-Umehara, C. Chen, D. Urich et al., "Suppression of inflammation and acute lung injury by Mizl via repression of C/EBP-delta," Nature Immunology, vol. 14, pp. 461-469, 2013.

[58] T. Cotechini, M. Komisarenko, A. Sperou, S. MacdonaldGoodfellow, M. A. Adams, and C. H. Graham, "Inflammation in rat pregnancy inhibits spiral artery remodeling leading to fetal growth restriction and features of preeclampsia," Journal of Experimental Medicine, vol. 211, no. 1, pp. 165-179, 2014.

[59] J. Zhou, H. Miao, X. Li, Y. Hu, H. Sun, and Y. Hou, "Curcumin inhibits placental inflammation to ameliorate LPS-induced adverse pregnancy outcomes in mice via upregulation of phosphorylated Akt," Inflammatory Research, vol. 66, no. 2, pp. 177-185, 2017.

[60] X. Xu, P. Yin, C. Wan et al., "Punicalagin inhibits inflammation in LPS-induced RAW264.7 macrophages via the suppression of TLR4-mediated MAPKs and NF-kappaB activation," Inflammation, vol. 37, pp. 956-965, 2014.

[61] R. G. Osmers, B. C. Adelmann-Grill, W. Rath, H. W. Stuhlsatz, H. Tschesche, and W. Kuhn, "Biochemical events in cervical ripening dilatation during pregnancy and parturition," Journal of Obstetrics and Gynecology, vol. 21, no. 2, pp. 185-194, 1995.

[62] J. C. Condon, P. Jeyasuria, J. M. Faust, and C. R. Mendelson, "Surfactant protein secreted by the maturing mouse fetal lung acts as a hormone that signals the initiation of parturition," Proceedings of the National Academy of Sciences of the United States of America, vol. 101, no. 14, pp. 4978-4983, 2004.

[63] W. Liu, C. Xu, X. You et al., "Hydrogen sulfide delays LPS-induced preterm birth in mice via anti-inflammatory pathways," PLoS One, vol. 11, no. 4, article e0152838, 2016.

[64] D. A. MacIntyre, Y. S. Lee, R. Migale et al., "Protein 1 is a key terminal mediator of inflammation-induced preterm labor in mice," Federation of American Societies of Experimental Biology Journal, vol. 28, pp. 2358-2368, 2014.

[65] M. Qin, R. Wang, C. Li, X. L. Liu, L. H. Qin, and H. P. Liu, "Establishment of decidual cell apoptotic models induced by tumor necrosis factor alpha and effects of baicalin on decidual cell apoptosis," Journal of Clinical Rehabilitative
Tissue Engineering Research, vol. 11, no. 19, pp. 3793-3796, 2007.

[66] D. A. Clark, J. Manuel, L. Lee, G. Chaouat, R. M. Gorczynski, and G. A. Levy, "Ecology of danger-dependent cytokineboosted spontaneous abortion in the CBA $x$ DBA/2 mouse model. I. Synergistic effect of LPS (TNF- $\alpha+$ IFN- $\gamma$ ) on pregnancy loss," American Journal of Reproductive Immunology, vol. 52, no. 6, pp. 370-378, 2004.

[67] S. Daher, K. Arruda Geraldes Denardi, M. H. Blotta et al., "Cytokines in recurrent pregnancy loss," Journal of Reproductive Immunology, vol. 62, no. 1-2, pp. 151-157, 2004.

[68] X. Wang, Y. Zhao, and X. Zhong, "Protective effects of baicalin on decidua cells of LPS-induced mice abortion," Journal of Immunology Research, vol. 2014, Article ID 859812, 6 pages, 2014.

[69] J. S. Chua, A. M. Rofe, and P. Coyle, "Dietary zinc supplementation ameliorates LPS-induced teratogenicity in mice," Pediatric Research, vol. 59, no. 3, pp. 355-358, 2006.

[70] T. M. Leazer, B. Barbee, M. Ebron-McCoy, G. A. Henry-Sam, and J. M. Rogers, "Role of the maternal acute phase response and tumor necrosis factor alpha in the developmental toxicity of lipopolysaccharide in the CD-1 mouse," Reproductive Toxicology, vol. 16, pp. 173-179, 2002.

[71] H. Ning, H. Wang, L. Zhao et al., "Maternally-administered lipopolysaccharide (LPS) increases tumor necrosis factor alpha in fetal liver and fetal brain: its suppression by low-dose LPS pretreatment," Toxicology Letters, vol. 176, pp. 13-19, 2008.

[72] H. Ashdown, Y. Dumont, M. Ng, S. Poole, P. Boksa, and G. N. Luheshi, "The role of cytokines in mediating effects of prenatal infection on the fetus: implications for schizophrenia," Molecular Psychiatry, vol. 11, pp. 47-55, 2006.

[73] M. D. Shah and S. R. Shah, "Nutrient deficiencies in the premature infant," Pediatric Clinics of North America, vol. 56, no. 5, pp. 1069-1083, 2009.

[74] N. G. Than, R. Romero, A. L. Tarca et al., "Mitochondrial manganese superoxide dismutase mRNA expression in human chorioamniotic membranes and its association with labor, inflammation, and infection," Journal of Maternal and Fetal Neonatal Medicine, vol. 22, no. 11, pp. 10001013, 2009.

[75] J. Lorenz, E. Seebach, G. Hackmayer et al., "Melanocortin 1 receptor-signaling deficiency results in an articular cartilage phenotype and accelerates pathogenesis of surgically induced murine osteoarthritis," PLoS One, vol. 9, no. 9, article e105858, 2014.

[76] J. F. Ge, Y. Ji, and Y. Zhang, "Clinical analysis of 81 premature infants with early-onset sepsis," Chinese Journal of Practical Medicine, vol. 43, no. 17, pp. 77-79, 2016.

[77] S. P. Zhen, S. Lu, and Z. H. Wang, "Review on screening of cervical lesions and pregnancy outcome by using liquid based cytology and HPV joint fractal detection in gestation period," Chinese Foreign Medical Research, vol. 14, no. 11, pp. 44-45, 2016.

[78] C. Y. Yuan, "Analysis the effect of diabetes in gestation period on puerperal and newborn," Women's Health Research, vol. 11, no. 14, p. 230, 2016.

[79] Y. Z. Guo, P. He, and A. M. Feng, "Effect of curcumin on expressions of NF-kBp65, TNF-a and IL-8 in placental tissue of premature birth of infected mice," Asian Pacific Journal of Tropical Medicine, vol. 10, no. 2, pp. 175-178, 2017. 
[80] American College of Obstetricians and Gynecologists, "Hypertension in pregnancy: report of the American College of Obstetricians and Gynecologists' task force on hypertension in pregnancy," Obstetrics and Gynecology, vol. 122, p. 1122, 2013.

[81] C. W. Redman and I. L. Sargent, "Latest advances in understanding preeclampsia," Science, vol. 308, pp. 1592-1594, 2005.

[82] J. M. Roberts and C. A. Hubel, "Oxidative stress in preeclampsia," American Journal of Obstetrics and Gynecology, vol. 190, pp. 1177-1178, 2004.

[83] G. J. Burton, H. W. Yung, T. Cindrova-Davies, and D. S. Charnock-Jones, "Placental endoplasmic reticulum stress and oxidative stress in the pathophysiology of unexplained intrauterine growth restriction and early onset preeclampsia," Placenta, vol. 30, pp. 43-48, 2009.

[84] J. M. Roberts and C. A. Hubel, "Is oxidative stress the link in the two-stage model of pre-eclampsia?," Lancet, vol. 354, pp. 788-789, 1999.

[85] X. J. Liu, B. W. Wang, M. Zhao et al., "Effects of maternal LPS exposure during pregnancy on metabolic phenotypes in female offspring," PLoS One, vol. 9, no. 12, article e114780, 2014.

[86] P. Saenger, P. Czernichow, I. Hughes, and E. O. Reiter, "Small for gestational age: short stature and beyond," Endocrine Reviews, vol. 28, pp. 219-251, 2007.

[87] Y. Seki, L. Williams, P. M. Vuguin, and M. J. Charron, "Minireview: epigenetic programming of diabetes and obesity: animal models," Endocrinology, vol. 153, pp. 10311038, 2012

[88] V. V. Bol, A. I. Delattre, B. Reusens, M. Raes, and C. Remacle, "Forced catch-up growth after fetal protein restriction alters the adipose tissue gene expression program leading to obesity in adult mice," American Journal of Physiology and Regulatory Integrative and Comparative Physiology, vol. 297, pp. R291-R299, 2009.

[89] U. Kamath, G. Rao, S. U. Kamath, and L. Rai, "Maternal and fetal indicators of oxidative stress during intrauterine growth retardation (IUGR)," Indian Journal of Clinical Biochemistry, vol. 21, pp. 111-115, 2006.

[90] Z. Hracsko, H. Orvos, Z. Novak, A. Pal, and I. S. Varga, "Evaluation of oxidative stress markers in neonates with intra-uterine growth retardation," Redox Reports, vol. 13, pp. 11-16, 2008.

[91] S. J. Chapple, X. Cheng, and G. E. Mann, "Effects of 4hydroxynonenal on vascular endothelial and smooth muscle cell redox signaling and function in health and disease," Redox Biology, vol. 1, pp. 319-331, 2013.

[92] S. J. Chapple, R. C. Siow, and G. E. Mann, "Crosstalk between $\mathrm{Nrf} 2$ and the proteasome: therapeutic potential of Nrf2 inducers in vascular disease and aging," International Journal of Biochemistry and Cellular Biology, vol. 44, pp. 1315-1320, 2012.

[93] T. Ishii, K. Itoh, E. Ruiz et al., "Role of Nrf2 in the regulation of CD36 and stress protein expression in murine macrophages: activation by oxidatively modified LDL and 4-hydroxynonenal," Circulatory Research, vol. 94, pp. 609-616, 2004.

[94] S. B. Cullinan, J. D. Gordan, J. Jin, J. W. Harper, and J. A. Diehl, "The Keap1-BTB protein is an adaptor that bridges $\mathrm{Nrf} 2$ to a Cul3-based E3 ligase: oxidative stress sensing by a
Cul3-Keap1 ligase," Molecular and Cellular Biology, vol. 24, pp. 8477-8486, 2004.

[95] K. Taguchi, H. Motohashi, and M. Yamamoto, "Molecular mechanisms of the Keap1-Nrf2 pathway in stress response and cancer evolution," Genes to Cells, vol. 16, pp. 123-140, 2011.

[96] A. T. Dinkova-Kostova and P. Talalay, "NAD(P)H:quinone acceptor oxidoreductase 1 (NQO1), a multifunctional antioxidant enzyme and exceptionally versatile cytoprotector," Archives of Biochemistry and Biophysics, vol. 501, pp. 116$123,2010$.

[97] R. C. Siow, H. Sato, and G. E. Mann, "Heme oxygenasecarbon monoxide signalling pathway in atherosclerosis: anti-atherogenic actions of bilirubin and carbon monoxide?," Cardiovascular Research, vol. 41, pp. 385-394, 1999.

[98] C. C. Franklin, D. S. Backos, I. Mohar, C. C. White, H. J. Forman, and T. J. Kavanagh, "Structure, function, and post-translational regulation of the catalytic and modifier subunits of glutamate cysteine ligase," Molecular Aspects of Medicine, vol. 30, pp. 86-98, 2009.

[99] H. Sato, M. Tamba, K. Kuriyama-Matsumura, S. Okuno, and S. Bannai, "Molecular cloning and expression of human xCT, the light chain of amino acid transport system xc," Antioxidant and Redox Signaling, vol. 2, pp. 665-671, 2000.

[100] L. E. Tebay, S. T. Durant, S. R. Vitale, T. Penning, A. T. Dinkova-Kostova, and J. D. Hayes, "Mechanisms of activation of the transcription factor Nrf2 by redox stressors, nutrient cues, and energy status and the pathways through it attenuates degenerative disease," Free Radicals Biology and Medicines, vol. 88, pp. 108-146, 2015.

[101] N. Kweider, J. Lambertz, T. Pufe, C. J. Wruck, and W. Rath, "[125-POS]: Nrf2 deficiency interferes with trophoblast differentiation and affects the placental development in mice," Pregnancy Hypertension, vol. 5, pp. 66-67, 2015.

[102] A. Ramkissoon and P. G. Wells, "Developmental role of nuclear factor E2-related factor 2 in mitigating methamphetamine fetal toxicity and postnatal neurodevelopmental deficits," Free Radical Biology \& Medicine, vol. 65, pp. 620631, 2013.

[103] A. Zheng, H. Li, K. Cao et al., "Maternal hydroxytyrosol administration improves neurogenesis and cognitive function in prenatally stressed offspring," Journal of Nutritional Biochemistry, vol. 26, pp. 190-199, 2015.

[104] X. Chen, J. Liu, and S. Y. Chen, "Sulforaphane protects against ethanol-induced oxidative stress and apoptosis in neural crest cells by the induction of Nrf2-mediated antioxidant response," British Journal of Pharmacology, vol. 169, pp. 437-448, 2013.

[105] F. Lin, X. Yu, X. Zhang et al., "A synthetic analog of lipoxin A4 partially alleviates dexamethasone-induced fetal growth restriction in rats," Placenta, vol. 34, pp. 941-948, 2013.

[106] A. J. Huebner, D. Dai, M. Morasso et al., "Amniotic fluid activates the Nrf2/keap1 pathway to repair an epidermal barrier defect in utero," Developmental Cell, vol. 23, pp. 1238-1246, 2012.

[107] P. Wentzel and U. J. Eriksson, “Altered gene expression in rat cranial neural crest cells exposed to a teratogenic glucose concentration in vitro: paradoxical downregulation of antioxidative defense genes," Birth Defects Research Part B, Developmental and Reproductive Toxicology, vol. 92, pp. 487-497, 2011. 
[108] S. Y. Chang, Y. W. Chen, X. P. Zhao et al., "Catalase prevents maternal diabetes-induced perinatal programming via the Nrf2-HO-1 defense system," Diabetes, vol. 61, pp. 25652574, 2012.

[109] N. Acar, H. Soylu, I. Edizer et al., "Expression of nuclear factor erythroid 2-related factor 2 (Nrf2) and peroxiredoxin $6(\operatorname{Prdx} 6)$ proteins in healthy and pathologic placentas of human and rat," Acta Histochemica, vol. 116, pp. 12891300, 2014.

[110] Y. Chigusa, K. Tatsumi, E. Kondoh et al., "Decreased lectin-like oxidized LDL receptor 1 (LOX-1) and low Nrf2 activation in placenta are involved in preeclampsia," Journal of Clinical Endocrinology and Metabolism, vol. 97, pp. E1862-E1870, 2012.

[111] A. Maebayashi Asanuma, T. Yamamoto, H. Azuma et al., "Expression of placenta growth factor, soluble fms-like tyrosine kinase-1, metal-responsive transcription factor-1, heme oxygenase 1 and hypoxia inducible factor-1alpha mRNAs in pre-eclampsia placenta and the effect of pre-eclampsia sera on their expression of choriocarcinoma cells," The Journal of Obstetrics and Gynaecology Research, vol. 40, pp. 20952103, 2014.

[112] X. Cheng, S. J. Chapple, B. Patel et al., "Gestational diabetes mellitus impairs Nrf2-mediated adaptive antioxidant defenses and redox signaling in fetal endothelial cells in utero," Diabetes, vol. 62, pp. 4088-4097, 2013.

[113] A. Zheng, H. Li, K. Cao et al., "Maternal hydroxytyrosol administration improves neurogenesis and cognitive function in prenatally stressed offspring," Journal of Nutritional Biochemistry, vol. 26, pp. 190-199, 2015.

[114] Y. J. Wan, Y. Y. Li, W. Xia et al., "Alterations in tumor biomarker GSTP gene methylation patterns induced by prenatal exposure to PFOS," Toxicology, vol. 274, pp. 57-64, 2010.

[115] S. A. McGrath-Morrow, T. Lauer, J. M. Collaco et al., "Transcriptional responses of neonatal mouse lung to hyperoxia by Nrf2 status," Cytokine, vol. 65, pp. 4-9, 2014.

[116] J. Dong, K. K. Sulik, and S. Y. Chen, "Nrf2-mediated transcriptional induction of antioxidant response in mouse embryos exposed to ethanol in vivo: implications for the prevention of fetal alcohol spectrum disorders," Antioxidants and Redox Signaling, vol. 10, pp. 20232033, 2008.

[117] C. Harris and J. M. Hansen, "Nrf2-mediated resistance to oxidant-induced redox disruption in embryos," Birth Defects Research Part B, Developmental Reproductive Toxicology, vol. 95, pp. 213-218, 2012.

[118] G. Agati, E. Azzarell, S. Pollastri, and M. Tattini, "Flavonoids as antioxidants in plants: location and functional significance," Plant Science, vol. 196, pp. 67-76, 2012.

[119] P. V. Babu, D. Liu, and E. R. Gilbert, "Recent advances in understanding the anti-diabetic actions of dietary flavonoids," Journal of Nutritional Biochemistry, vol. 24, pp. 1777-1789, 2013.

[120] W. Jiang, H. Wei, and B. He, "Dietary flavonoids intake and the risk of coronary heart disease: a dose-response metaanalysis of 15 prospective studies," Thrombosis Research, vol. 135, pp. 459-463, 2015.

[121] S. Venturelli, M. Burkard, M. Biendl, U. M. Lauer, J. Frank, and C. Busch, "Prenylated chalcones and flavonoids for the prevention and treatment of cancer," Nutrition, vol. 32, no. 11-12, pp. 1171-1178, 2016.
[122] V. Kumar, A. K. Abbas, N. Fausto, and R. N. Mitchell, Robbins Basic Pathology, Elsevier Health Sciences, Philadephia, PA, USA, 2012.

[123] M. Proell, S. J. Riedl, J. H. Fritz, A. M. Rojas, and R. Schwarzenbacher, "The nod-like receptor (NLR) family: a tale of similarities and differences," PLoS One, vol. 3, p. 921, 2008.

[124] T. Cotechini, M. Komisarenko, A. Sperou, S. MacdonaldGoodfellow, M. A. Adams, and C. H. Graham, "Inflammation in rat pregnancy inhibits spiral artery remodeling leading to fetal growth restriction and features of preeclampsia," Journal of Experimental Medicine, vol. 211, no. 1, pp. 165-179, 2014.

[125] A. Sharma, A. Satyam, and J. B. Sharma, "Leptin, IL-10 and inflammatory markers (TNF-a, IL-6 and IL-8) in pre-eclamptic, normotensive pregnant and healthy non-pregnant women," American Journal of Reproductive Immunology, vol. 58, pp. 21-30, 2007.

[126] R. L. Prior, L. Gu, X. Wu et al., "Plasma antioxidant capacity changes following a meal as a measure of the ability of a food to alter in vivo antioxidant status," Journal of American College of Nutrition, vol. 26, pp. 170-181, 2007.

[127] Y. H. Chen, M. Zhao, X. Chen et al., "Zinc supplementation during pregnancy protects against lipopolysaccharideinduced fetal growth restriction and demise through its anti-inflammatory effect," Journal of Immunology, vol. 189, pp. 454-463, 2012.

[128] S. Kumar and A. K. Pandey, "Chemistry and biological activities of flavonoids: an overview," Scientific World Journal, vol. 2013, Article ID 162750, 16 pages, 2013.

[129] Y. L. Lin, C. Y. Cheng, Y. P. Lin, Y. W. Lau, I. M. Juan, and J. K. Lin, "Hypolipidemic effect of green tea leaves through induction of antioxidant and phase II enzymes including superoxide dismutase, catalase, and glutathioneS-transferase in rats," Journal of Agriculture and Food Chemistry, vol. 46, pp. 1893-1899, 1998.

[130] K. H. Al-Gubory, P. A. Fowler, and C. Garrel, "The roles of cellular reactive oxygen species, oxidative stress and antioxidants in pregnancy outcomes," International Journal of Biochemistry and Cellular Biology, vol. 42, no. 10, pp. 1634-1650, 2010.

[131] K. Vanhees, F. J. van Schooten, S. B. van Waalwijk van Doorn-Khosrovani et al., "Intrauterine exposure to flavonoids modifies antioxidant status at adulthood and decreases oxidative stress-induced DNA damage," Free Radicals Biology and Medicine, vol. 57, pp. 154-161, 2013.

[132] J. D. Hartley, B. J. Ferguson, and A. Moffett, "The role of shed placental DNA in the systemic inflammatory syndrome of preeclampsia," American Journal of Obstetrics and Gynecology, vol. 213, no. 3, pp. 268-277, 2015.

[133] V. Shalini, C. K. Pushpan, G. Sindhu, and A. Helen, "Tricin, flavonoid from Njavara reduces inflammatory responses in hPBMCs by modulating the p38MAPK and PI3K/Akt pathway and prevents inflammation associated endothelial dysfunction in HUVECs," Immunobiology, vol. 221, no. 2, pp. 137-144, 2016.

[134] G. Scapagnini, V. Sonya, A. G. Nader, C. Calogero, D. Zella, and G. Fabio, "Modulation of Nrf2/ARE pathway by food polyphenols: a nutritional neuroprotective strategy for cognitive and neurodegenerative disorders," Molecular Neurobiology, vol. 44, no. 2, pp. 192-201, 2011.

[135] H. K. Na, E. H. Kim, J. H. Jung, H. H. Lee, J. W. Hyun, and Y. J. Surh, "(-)-Epigallocatechin gallate induces 
Nrf2-mediated antioxidant enzyme expression via activation of PI3K and ERK in human mammary epithelial cells," Archives of Biochemistry and Biophysics, vol. 476, pp. 171-177, 2008.

[136] X. Wang, A. Ma, W. Shi, M. Geng, X. Zhong, and Y. Zhao, "Quercetin and bornyl acetate regulate T-lymphocyte subsets and INF-/IL-4 ratio in utero in pregnant mice," EvidenceBased Complementary and Alternative Medicine, vol. 2011, Article ID 745262, 7 pages, 2011.

[137] X. H. Zhong, W. Y. Shi, A. T. Ma et al., "Effects of Radix Scutellariae and Rhizoma Atractylodis on LPS-induced abortion and the uterine IL-10 contents in mice," American Journal of Chinese Medicine, vol. 36, pp. 141-148, 2008.

[138] C. Li, G. Lin, and Z. Zuo, "Pharmacological effects and pharmacokinetics properties of Radix Scutellariae and its bioactive flavones," Biopharmaceutics \& Drug Disposition, vol. 32, no. 8, pp. 427-445.

[139] X. Zhong and Y. Zhao, "Anti-abortive effects of Bao Tai Wu You, Tai Shan Pan Shi and Bai Zhu San in a murine mode," American Journal of Traditional Chinese Veterinary Medicine, vol. 8, no. 2, 2013. 


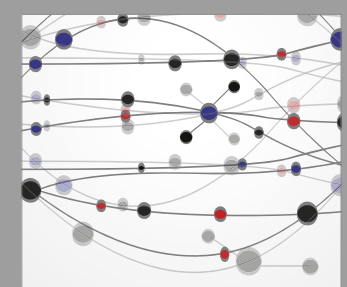

The Scientific World Journal
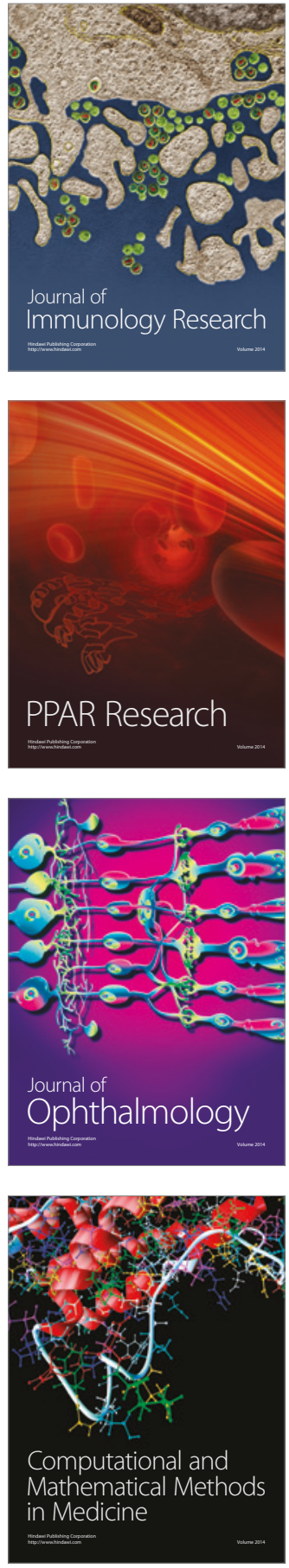

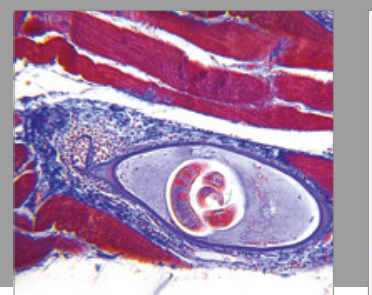

Gastroenterology Research and Practice
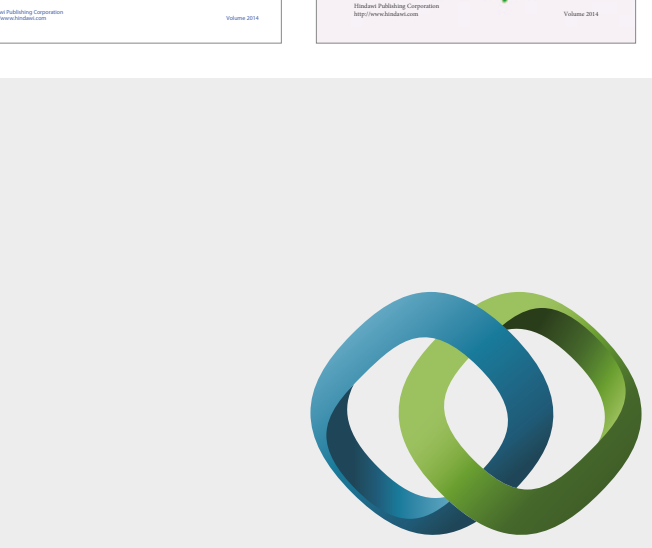

\section{Hindawi}

Submit your manuscripts at

https://www.hindawi.com
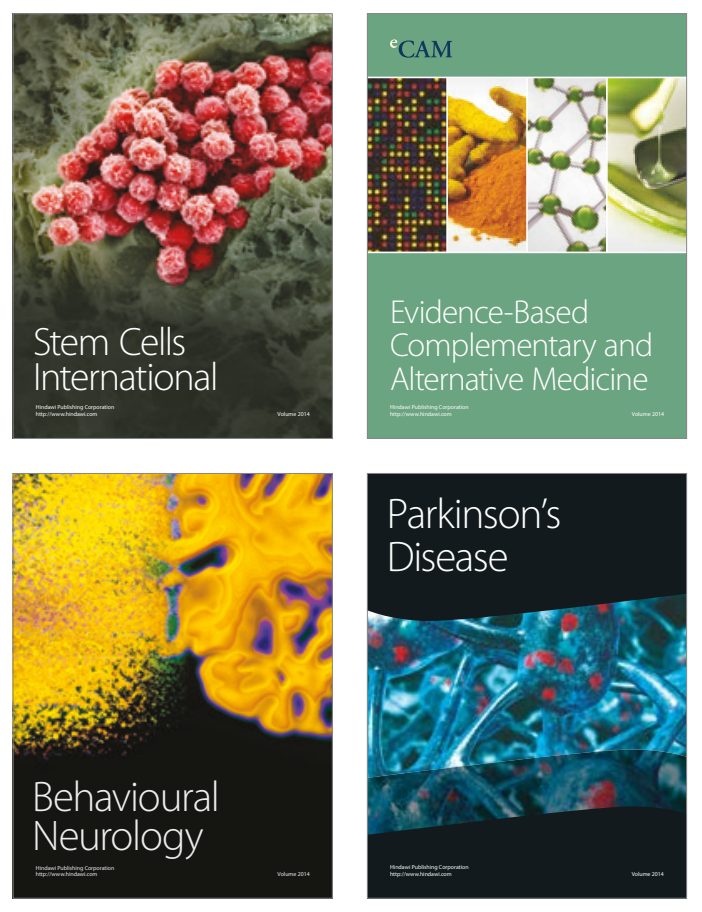
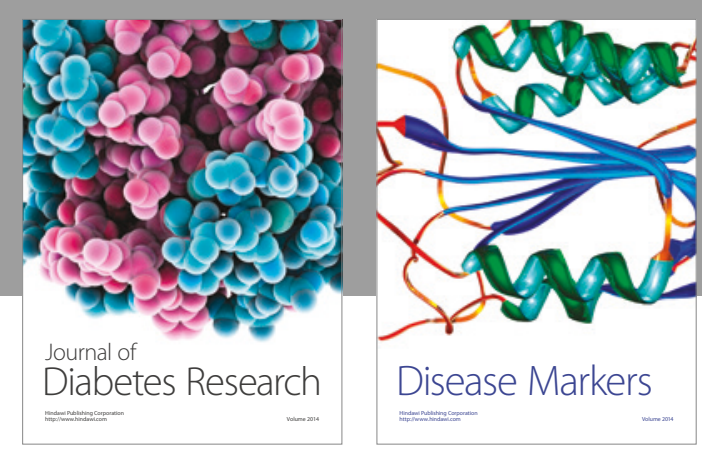

Disease Markers
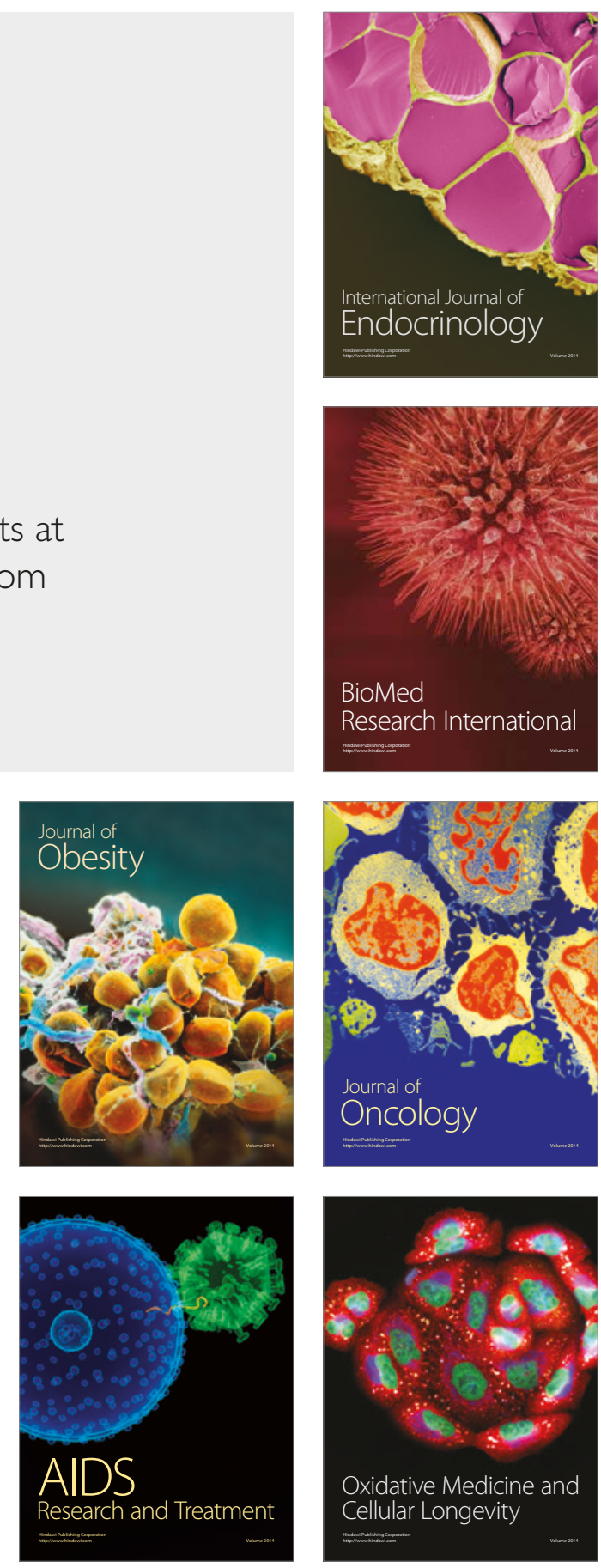